\title{
LA SOLEDAd DE LAS Guerreras de SANTA MARTHA
}

\author{
THE LONELINESS OF SANTA MARTHA'S WARRIORS
}

\author{
Ángel AlONSO SALAS \\ iberoangina@yahoo.com.mx \\ Universidad Nacional Autónoma de México
}

RECIBIDO: 20 DE JULIO DE 2018

ACEPTADO: 2 DE OCTUBRE DE 2018

Resumen: En el presente texto se reflexionará acerca de la soledad que padecen las personas privadas de su libertad en el Reclusorio Femenil de Santa Martha Acatitla en la Ciudad de México, y la manera en que los Talleres de Filosofía (que se imparten desde mayo de 2017) se han convertido en un bálsamo ante la exclusión, marginación, victimización y vida fútil en la que se encuentra una mujer que ha sido privada de su libertad, y, que se encuentra en espera de una sentencia o cumpliendo una condena en el interior de dicho centro penal.

Palabras clave: Soledad, mujer, filosofía, reclusorio, sufrimiento.

Abstract: In this text it will reflect about the loneliness suffered by people deprived of their liberty in the Women's Prison of Santa Martha Acatitla in Mexico City, and the way in which the Philosophy Workshops (since 2017) have become a balm to exclusion, marginalization, victimization and futile life in which a woman who has been deprived on her liberty, and, who is waiting a sentence or serving a sentence inside of this penal centre.

Keywords: Lonliness, women, philosophy, prison, suffering

A lo largo de este escrito se reflexionará la manera en que la sociedad ha convertido a las mujeres privadas de su libertad, en vidas fútiles, desechables y solitarias, así como también el hecho de que sufren una exclusión y victimización, no sólo por el motivo u acción que las llevó a dicho lugar, sino que, por el simple hecho de ser mujer, la condena social que les es impuesta y que padecen es desproporcionada y humillante. 
Iniciemos con una pregunta: ¿es posible hacer filosofía en el interior de los reclusorios? Dicho cuestionamiento referente a la viabilidad y factibilidad de hacer filosofía en el interior de reclusorios tiene una respuesta es muy sencilla: SÍ. Basta recordar que El príncipe de Maquiavelo, Cartas a Olga de Václv Havel, El ingenioso hidalgo don Quijote de la Mancha de Miguel de Cervantes Saavedra, El Apando de José Revueltas, o, los Cuadernos desde la cárcel de Antonio Gramsci, fueron obras concebidas y escritas desde el interior de una cárcel, en donde dichos autores lograron escribir sus reflexiones sobre diversos aspectos de la condición humana y que a la postre fueron publicados y difundidos. Pero ¿existe algún registro de obras literarias, históricas o filosóficas realizadas por una mujer y que tengan la misma resonancia que las obras de varones mencionadas con antelación? ¿Existe algo más que un "reportaje" sobre las mujeres en alguna prisión? ¿Acaso la "exclusión" y cuestión de género es un factor que determina aún más la estancia y condena hacia las mujeres que a los varones?

En este breve escrito se compartirá las actividades que se llevan a cabo en el taller de Filosofía que se imparte en el interior del Reclusorio Femenil de Santa Martha Acatitla, en Ciudad de México, actividad que se ha convertido en un bálsamo para las mujeres privadas de su libertad y que ofrece herramientas para trabajar con la soledad en la que están inmersas.

El proyecto de "Talleres de Filosofía" surgió en 2017 a raíz de que uno de mis alumnos de la Licenciatura en Filosofía en la FES Acatlán, UNAM, Marco Antonio López Cortés, llevó a cabo su servicio social con la impartición de un Taller de Filosofía para personas privadas de su libertad. El taller se llevó a cabo en el segundo semestre de 2017 en el Centro de Ejecuciones y Sanciones Penales Varonil Oriente (CESPVO) del Reclusorio Oriente y en el Reclusorio Femenil de Santa Martha Acatitla, ambos en la Ciudad de México -y que en dichos penales se maneja por trimestre o 
cuatrimestre, respectivamente-. Dicho proyecto tiene como objetivo principal el brindar las herramientas y contendidos filosóficos que le permitan a la persona privada de su libertad reflexionar sobre su vida, el sentido y significación que puede tener la reclusión a partir de la puesta en práctica de nociones y así hacer más "soportable" su estancia en prisión, con miras de que se coadyuvar a la reinserción social.

Entre los resultados que se obtuvieron de dicho taller se pueden destacar que se contribuyó a disminuir el nivel de consumo de drogas y menguó la adicción de ciertas personas privadas de su libertad; muchos (as) de los internos (as) asumieron y pusieron en práctica los contenidos del Taller (filosofía griega, existencialismo y poesía); algunas personas abandonaron la idea suicida que estaban tramando; en el penal femenil se formaron equipos de fútbol americano (tochito) y basquetbol; se generó un interés genuino por los contenidos filosóficos, al grado de que al término del servicio social, el estudiantado de ambos centros penitenciarios, solicitaron la continuidad de los talleres.

Fui testigo del proceso de Marco López frente a los talleres, y, en la mesa de clausura, con el apoyo de decenas de estudiantes, profesores y amistades se llevó a cabo una colecta de más de 400 libros y útiles escolares que fueron entregados en ambas sedes de los Talleres de Filosofía. En la mesa de clausura, conocí a las alumnas de Santa Martha, y, hablé desde la perspectiva nietzscheana acerca del sentido de la vida que existe ante el absurdo o sinsentido de esta. Platiqué con muchas de las asistentes quienes me contaron sus impresiones del Taller; lo mucho que les sirvieron las clases y los grandes problemas que padecen en el interior del penal, ya que, difícilmente los visitan sus familiares, cónyuges o hijos; que no cuentan con el suficiente dinero para adquirir utensilios básicos; el hecho de que no reciben visitas conyugales a menos que hayan contraído matrimonio por el registro civil; la existencia de un 20 o $25 \%$ de analfabetismo en el 
interior del penal; que para algunas de ellas la mesa en la que un servidor había participado significaba la visita de alguien de "afuera" que hacía años que no tenían; que no pudieron asistir a la velación y sepultura de algún familiar, pues lo más que pueden hacer es ver el féretro si éste se acerca a la entrada del penal y se hacen las debidas diligencias y así despedirse de dicho ser querido; que agradecían infinitamente que estando "afuera", rompiera con los prejuicios y soportara todos los protocolos de ingreso al penal para hablarles del sentido de la vida, entre otras historias duras, difíciles y dolorosas de personas que se encuentran privadas de su libertad.

Ante todo este escenario y peticiones, el Taller de Filosofía sigue impartiéndose hoy día y este escrito es para dar voz al efecto balsámico y esperanzador que ha tenido la impronta estos cursos durante el periodo de servicio social que efectuó Marco (2017) y a lo largo de este 2018, donde hemos invitado a diversos estudiantes y distintos profesores a que sean partícipes de estos talleres, y, que en este cuatrimestre, un servidor coordina el Taller de Filosofía en Santa Martha, ya que Marco López se ha concentrado en el CESPVO para continuar con su proceso de titulación. En la mesa de clausura del segundo cuatrimestre de 2017 , celebrada el $1^{\circ}$ de diciembre, una de las integrantes del Taller, Selene Guerra afirmó que:

estando en reclusión, un lugar tan lúgubre donde el dolor, la tristeza y desolación abundan, donde personalmente me despojó de todo al llegar aquí. Afortunadamente, después de un tiempo llegó el Taller de Filosofía. Fue como conocer otro mundo, uno muy diferente: como abrir puertas, cruzar fronteras, atravesar muros, acortar distancias, revelar emociones [...] Me ha ayudado a ver la vida de manera diferente, cuestionarme todo, ampliar mis ideas, pensamientos, libros de personajes como Sócrates y Platón, y en algunas novelas renombradas de grandes autores.

Disfruto al compartir esto con todo mi alrededor, así como con amigos, compañeras, familia e hijos, con la intención de despertar 
el mismo interés y/o curiosidad, o el simple hecho de transmitir el conocimiento. Por ejemplo, en mi estancia, después del cierre les comentaba a mis compañeras lo que habíamos leído en clase y ellas me pedían que se los leyera. [...] Me ha gustado tanto la filosofía, por tantas razones. Alimenta mi alma, fortalece mi espíritu, serena mis emociones y abre mi mente alegrando mi corazón [...] De las mejores cosas que me pudieron haber pasado en esta reclusión fue sin lugar a dudas, conocer la filosofía y a mi profesor Marco Antonio López Cortés [...] La filosofía ha provocado estar al pendiente de la información actual, tener mi propia opinión; criterio amplio; no dejarme llevar por lo establecido y menos por otras personas. Con esto me refiero a los engaños y entretenimientos del gobierno y los medios de comunicación.

Me hubiera gustado conocer esta clase antes, tal vez mi vida hubiera sido diferente $[\ldots]$ La filosofía llegó en una etapa de mi vida en reclusión muy crítica, pero a través de ésta, me pareció o lo tomé como una terapia que me ayudó a subir mi ánimo y a sobresalir de mi sentir. Esta clase me ha servido en otras áreas de mi vida en reclusión (como el teatro). Sin exagerar, ha cambiado mi vida y seguirá siendo cuando reciba mi libertad. Estoy ansiosa de transmitirlo a los míos, que no he visto [...] Así aplica la filosofía en Selene. Ser constante en ese cambio, para ser mejor ser humano, mejor mujer, mejor pareja, mejor amiga y mejor madre. ¡Ha sido mi luz en este camino! Agradezco a quienes hicieron posible que este Taller sea impartido en el penal. Que así siga siendo porque estoy segura que cambiará la vida de alguien más como yo ${ }^{1}$.

Veamos a continuación qué temas se han abordado en el taller a raíz del Servicio Social que llevó a cabo Marco López y que él reportará los detalles de esos cuatrimestres en su trabajo de investigación para obtener el grado de Licenciatura en Filosofía por la UNAM.

$* *$

${ }^{1}$ GUERRA GARCÍA, Selene Patricia: "Mi experiencia en el taller de filosofía de Santa Martha Acatitla", disponible on-line en https://cefilibe.wordpress.com/page/1/ (último acceso 19 de octubre de 2018). 
Zygmunt Bauman en Vidas desperdiciadas. La modernidad y sus parias lleva a cabo una reflexión sobre las "vidas desperdiciadas", sobre la manera en que la modernidad está generando "residuos humanos", "vidas desechables" o seres fútiles, en donde existen masas de humanos que se han convertido en superfluas, tales como los migrantes, refugiados, y de todo ese cúmulo de personas que de manera despectiva llamamos "escoria humana", a las cuales buscamos eliminar, reciclar, o simplemente hacer como si "no existieran". Dicho con sus palabras:

ser «superfluo» significa ser supernumerario, innecesario, carente de uso -sean cuales fueren las necesidades y los usos que establecen el patrón de utilidad e indispensabilidad-. Los otros no te necesitan; pueden arreglárselas igual de bien, si no mejor, sin ti. No existe razón palmaria para tu presencia ni obvia justificación para tu reivindicación del derecho de seguir ahí. Que te declaren superfluo significa haber sido desechado por ser desechable, cual botella de plástico vacía y no retornable o jeringuilla usada; una mercancía poco atractiva sin compradores o un producto inferior y manchado, carente de utilidad, retirado de la cadena de montaje por los inspectores de calidad. «Superfluidad» comparte su espacio semántico con «personas o cosas rechazadas», «derroche», «basura», «desperdicios»: con residuo. Son consideradas como desechables o residuos [...] El destino de los residuos es el basurero, el vertedero ${ }^{2}$.

¿Y no acaso esto es lo que la sociedad se ha dedicado a hacer creer a sus ciudadanos y a convertir a las personas que están privadas de su libertad en algo "desagradable y desechable"? Uno de los principales argumentos que mencionan las mujeres privadas de su libertad es que, aunque la sociedad las etiquete como seres humanos aberrantes y carentes de utilidad, que sean señaladas

2 BAUMAN, Zygmunt. Vidas desperdiciadas. La modernidad y sus parias, Paidós, Buenos Aires, 2005, p. 32. 
como la escoria de la sociedad -mismas que deberían ser eliminadas o desechadas porque constituyen el peor aspecto e imagen de la sociedad mexicana-, esto constituye una falsa apreciación, ya que siguen siendo personas y poseen derechos humanos mínimos, así como el hecho de que estas apreciaciones en el fondo son juicios subjetivos carentes de sentido y sustento, en tanto que son argumentos falaces per se. En una ocasión, Diana, una de las chicas mencionó que "aquí en Santa Martha, entre las internas, no deberíamos ver al delito que provocó que una de nosotras estuviera aquí (aunque lo sepamos) y que ella fuera la encarnación de dicha acción (una homicida, secuestradora, defraudadora, pedófila, etcétera), sino que deberíamos ver a la mujer que ella misma representa, en tanto que cada una es con sus valores y sus defectos, su persona, ese ser humano, que es como tú y yo".

Osamos decir que toda persona por el simple derecho de ser persona tiene derechos, buscamos procurar una vida digna y con sentido a cualquier ser humano e inclusive hasta a primates superiores, pero les negamos este derecho a las personas recluidas y exiliadas en asilos, orfanatos, hospitales, a la gente indigente, a los que están en reclusorios, a los pueblos indígenas y a los migrantes que transitan en nuestras calles. ¿Qué incongruentes e hipócritas somos! La doble moral está a flor de piel y omnisciente en situaciones como las aquí descritas. Este sistema neoliberal, capitalista y de competencia te obliga a convertirte en alguien útil y productivo o en un desecho, en algo que se devalúa conforme pasa el tiempo... Desgraciadamente muchos de los que estamos "afuera" somos conscientes de esto hasta que somos desplazados por las nuevas generaciones; cuando no nos percatamos de la fijación que se tiene en verse joven y útil, por lo que el consumo de bottox, de buscar tener un cuerpo escultural en el gym o mediante las liposucciones, o simplemente, el tener categorías como "chavorucos" (adultos jóvenes) son acciones y acontecimientos que 
se convierten en gritos desesperados ante la cercanía de ser adultos o al ver a nuestros padres como adultos mayores, y percatarnos del hecho de la manera en que nuestros hijos o sobrinos crecen, nos enfrenta al envejecimiento y a ir siendo desplazados por gente más útil y capacitada que nosotros.

Ahora bien, dejemos a los de afuera y pensemos en quienes están dentro de un penal. ¿Cómo afrontar en el interior de esa prisión el paso del tiempo? ¿Cómo se mide el tiempo y qué es lo que ellas miden y añoran? ¿De qué forma la prisión las devalúa y aniquila de manera rotunda sus sueños y proyectos de vida? Alguno de ustedes podrá emitir algún juicio referente a las mujeres que han sido privadas de su libertad y que están allí porque lo merecen y eso es el sentir del vox populli. “¿Por qué mantenemos a unas asesinas?”, "iQue se mueran o se les dé una pena de muerte!", o "vota porque los presidiaros cumplan condenas de limpieza de calles y asistencia social para que se recupere lo perdido con su mantenimiento" son ideas y pensamientos que fluyen en redes sociales... Pero, seamos honestos y sinceros ila justicia se aplica de manera imparcial y efectiva en México? ¿Realmente existe una justicia imparcial y equitativa en la que la cuestión de género no marque una diferencia en un juicio o en una condena?

En Santa Martha he conocido personas (no números que residen en una estancia, sino mujeres de carne y hueso, que sufren y se alegran como cualquiera de los lectores de este texto) que fueron inculpadas y que son inocentes; quienes se vieron obligadas a aceptar consciente o inconscientemente la culpabilidad, un delito, una acción, o, simplemente porque actuaron en defensa propia ante la violencia intrafamiliar que llevó a cabo su "pareja"; por actuar ante alguna violación o en defensa de sus hijos, así como también, existen muchas personas que confiesan que cometieron un error y que están pagando las consecuencias de sus actos.

Es curioso, muchos lloran y sufren porque Jean Valjean en Les Misérables fue condenado a prisión injustamente por robar un pan, 
y, no somos capaces de ver a las y los Valjean en nuestra nación y en el interior de los reclusorios. En lo que respecta al sistema penitenciario, la mayoría de las personas son muy duras, crueles y miserables hacia el sexo y al género femenino. En el penal varonil frecuentemente hay personas que visitan a las personas privadas de su libertad, y existe una especie de culpabilidad social y familiar con el padre, hijo o hermano a quien se va a visitar. En cambio, con la mujer se es cruel. Los abogados o defensores de oficio difícilmente hacen su trabajo, les piden dinero u otros medios para lograr un amparo o agilizar la salida del penal. No se le visita porque avergüenza tener una madre, hermana o esposa allí; porque, así como se le deja toda la responsabilidad del hogar y del cuidado de sus hijos, ella tendrá que arreglárselas sola. Total, si está allí es "porque ella misma se lo buscó".

Si la chica llega embarazada al penal, a los seis años su hijo (a) debe abandonar el penal y se busca "colocar" (cual pieza) a dicho (a) infante en una fundación de adopción o en un Sistema Nacional para el Desarrollo Integral de la Familia (DIF), salvo que el cónyuge o familiar directo haga los respectivos trámites legales para la custodia de ese ser vivo. La carencia de vida amorosa y sentimental por parte de su pareja (que muchas veces ven a su cónyuge por última vez para firmar el divorcio) se suple por el amor entre las internas, lo que a muchas las cuestiona y conflictúa, pero que muchas de ellas se aferran a estas relaciones de lesbianismo para sentir cariño o para descubrir que son bisexuales y "hacer más soportable" su estancia. El martirio que supone que las madres que ya no vean a su hijo (a) y familiares mientras "purgan" la condena, o bien, el transitar por fechas como Navidad, 10 de mayo, el día del niño o un cumpleaños no son un día más, sino un acontecimiento que adquiere otra dimensión en el interior de un penal que se suele vivir en una amarga y profunda soledad y que la reclusión les hace recordar de que son vidas desechables, excluidas y marginadas a los que la sociedad evade y desearía eliminar. 
Bauman hace mención de que la modernidad ha generado sujetos innecesarios, fácilmente sustituibles, rechazados, fútiles y absurdos. Muchas personas emiten esos comentarios hacia las personas privadas de su libertad. Al llevar a cabo las clases en los Talleres hemos ido quitando a los de "afuera" y a las de "adentro" esas "etiquetas", esas ideas, prejuicios o sentimientos de que son vidas desechables. Más allá de que una persona esté o no privada de su libertad, NO es una vida desechable. Los Talleres de Filosofía han empoderado a las personas privadas de su libertad mediante las sesiones de los Diálogos de Platón, mitología, escuelas helénicas, sentido de la vida, derechos reproductivos, resiliencia, finitud, entre otros tópicos. Se brinda una esperanza y se muestra la valía, el significado y el sentido que tiene cada ser humano, esté privado o no de su libertad. Nuestras vidas no son inútiles ni desechables. Debemos ser los dueños de nuestra existencia, asumir la responsabilidad de nuestros actos y a pesar de que la mujer se encuentre privada de su libertad, se le culpe por su género, se le excluya, margine y humille por estar cumpliendo (o esperando) una sentencia, es una vida digna. Por tal motivo, cuando las chicas esperan su clase de filosofía (porque a veces los protocolos de seguridad, en las aduanas, son muy desgastantes y tardíos), siempre agradecen que alguien de "afuera" las mire, escuche y apoye con los temas que hacen soportable el infierno y soledad que las carcome.

En este contexto uno comprende que la filosofía en sí misma es liberadora, que es un bálsamo, que ofrece catarsis y obliga a tomar una postura auténtica ante la vida. La filosofía y sus enseñanzas se encarnan y tienen una dimensión distinta en el interior del penal. No se discute sobre la "mónada" de Leibniz, los modus tollendo tollens o el "giro copernicano de la ciencia", sino sobre la praxis del quehacer filosófico, se recupera la noción de "filosofía para la vida", se resignifica el "cuidado de sí" y el por qué y para qué estoy aquí. Filosofar en el interior de un reclusorio es revitalizar y otorgar 
otro sentido a la vida y a la libertad. Posibilita una reinvención del sentido y significado que le damos a nuestra existencia y al proyecto de vida que se tiene que dar desde la soledad, la (re) victimización, la exclusión y futilidad siempre presente y lacerante en quien ha sido privado de su libertad.

\section{$* * *$}

Es necesario trabajar en lo que se podría llamar "la soledad de las guerreras de Santa Martha". Norbert Elias en La soledad de los moribundos plantea que, tras el avance de la ciencia, tecnología y medicina, se ha desplazado a la muerte, escondiéndola "detrás de las bambalinas", ya que, al postergar la expectativa de vida, la muerte de cada uno de nosotros es cada vez más lejana. El problema de ese "aplazamiento" de la muerte es que genera una fobia, miedo o soledad a aquellas personas que, sin estar muertas físicamente, se encuentran "muertas en vida", deseando el morir lo más pronto posible. Si bien es cierto que el texto de Elias apela a la reflexión sobre la finitud y la manera en que afrontamos nuestra muerte y la del Otro, valdría la pena detenerse en algunas cuestiones y simplemente reflexionar desde la perspectiva de la soledad en la que se encuentra la mujer privada de su libertad en Santa Martha, en donde ellas mismas se autonombran "guerreras" en función de todas las luchas internas que llevan día a día en la estancia, con las custodias, al dialogar o negociar con los abogados, ante el abandono de la familia o debido a la tortuosa y difícil espera de la visita de los familiares, en la que muchas veces la renta de la mesa, sillas y de la preparación de la comida fue en vano, pues no llegó nadie o hacen una visita rápida de menos de una hora y la mujer en cuestión estuvo esperando cinco horas y varias semanas con antelación esperando dicha visita, por mencionar algunas situaciones. 
Elias considera que lo más difícil que se puede afrontar es el "tácito aislamiento de los seniles y moribundos de la comunidad de los vivos, el enfriamiento paulatino de sus relaciones con personas que contaban con su afecto, la separación de los demás en general, que eran quienes les proporcionaban sentido y sensación de seguridad". Basta que cambiemos los términos de "seniles y moribundos" y los sustituyamos por "mujeres privadas de su libertad", para que re-signifiquemos el texto de Elias en el interior de los centros penitenciarios. Inevitablemente "significa que también a [ellas] se les escinde cada vez más detrás de las bambalinas, es decir, que se les aísla"4. Esta caracterización de "detrás de las bambalinas" implica una exclusión o marginación de la vida social pública, ya sea porque ofende al colectivo, que nos hace recordar nuestra fragilidad o porque manifiesta nuestra futilidad y un velado reciclamiento de roles y funciones sociales, o bien, al hecho de que son marginadas porque no sabemos qué hacer con ese sector de la población sean tuberculosos, enfermos mentales, presos, sidosos, ancianos, personas con capacidades distintas, enfermos terminales, entre otros.

A juicio de Elias los moribundos y en este caso las mujeres privadas de su libertad, "necesitan más que nunca tener la sensación de que todavía no han perdido su significado que tenían para otras personas" ", ya que una de las pruebas más duras y penas que deben padecer quienes han sido privadas de su libertad es la soledad. ¿Y acaso no es esto el reto que procura resolver o atender la "reinserción social"? ¿Por qué motivo los sistemas penitenciarios y jurídicos dan por hecho la existencia o inutilidad de la reinserción social? Muchas de las actividades lúdicas, deportivas y humanistas tienen una incidencia real en la comunidad que se capacita en dichos talleres.

\footnotetext{
${ }^{3}$ ELIAS, Norbert. La soledad de los moribundos. FCE, México, 1987, p. 8

${ }^{4}$ Ibid., p. 20

${ }^{5}$ Ibid., p. 73
} 
El sociólogo alemán considera que "el concepto de soledad se refiere también a una persona que vive en medio de otras muchas pero que carece totalmente de importancia para ellas, siéndoles indiferentes que exista o que no exista" ${ }^{\text {, }}$ que es lo que vivimos o padecemos muchas personas que estamos "afuera" del penal, pero que, con los medios de comunicación masiva, la inercia del trabajo, la rutina de ir al shopping, al billar o a la discoteca, dicho sentimiento se anestesia, se esconde "detrás de las bambalinas", ya que, uno tiene mil y un distractores para evadir su soledad y el vacío interno que lo carcome, pero ¿cómo lleva a cabo dicha evasión aquella mujer que debe pasar lista tres veces al día, que cada esquina del panóptico del reclusorio y su vestimenta le recuerda y reitera que está sola y que ha sido etiquetada como infractora, como desechable e inútil? "Algo" (no alguien) que está allí pero no se sabe qué hacer con ella. Por más que una interna se sature de actividades académicas o deportivas, difícilmente se llenará ese vacío. Muchas de ellas tienen visitas "a cuenta gotas" y muchas de ellas tienen que esperar a que cuando le hagan una llamada por teléfono a algún ser querido, éste no cuelgue al escuchar la grabación que le dice y previene con el siguiente mensaje: "usted está recibiendo una llamada del penal femenil de Santa Martha, ¿desea aceptar esta llamada?" ¿Cómo encontrar un sentido a partir del "reseteo" en el que se ven obligadas a realizar al cruzar las paredes del penal y encontrar cientos de historias de dolor, iguales o peores que la que están cargando en soledad? Si para los moribundos "una de las últimas grandes alegrías que pueden recibir [...] es que las cuiden familiares y amigos, es una última prueba de cariño, una última señal de que significan algo para los demás" ", ¿cómo hacerlo en soledad o con horarios de restricciones de martes, jueves y fines de semana para recibir esas

\footnotetext{
${ }^{6}$ Ibid., pp. 81-82

${ }^{7}$ Ibid., p. 107
} 
visitas? ¿Cómo empezar de cero y sola en un penal? ¿Cómo ellas pueden estar al lado de los familiares que están enfermos o que fallecieron, si son las personas de afuera quienes deben tener la voluntad para irlas a visitar?

¿Cómo entender la soledad en Santa Martha? ¿Cómo nos afecta esta soledad a quienes estamos "afuera" o a quienes están privados de su libertad y carecen de una libertad física? Octavio Paz en el Laberinto de la soledad sostiene que "el sentimiento de soledad [...] no es una ilusión -como a veces lo es el de inferioridad- sino la expresión de un hecho real: somos, de verdad, distintos. Y, de verdad, estamos solos"». A lo largo de dicha obra, Paz considera que la condición del mexicano se ve agravada por la soledad que es común a la especie humana, ya que "el sentirse y el saberse solo, desprendido del mundo y ajeno a sí mismo, separado de sí, no es característica exclusiva del mexicano [...] La soledad es el fondo último de la condición humana [... El ser humano] es nostalgia y búsqueda de comunión. Por eso cada vez que se siente a sí mismo, se siente como carencia de otro, como soledad" "¿Y no acaso esto nos pasa cotidianamente? ¿Cuántas veces nos sentimos incompletos o vacíos y buscamos el estar acompañados, ocupados y evitamos la soledad? Estemos "dentro" o "fuera" del penal nos aterra la soledad, no estamos preparados (as) para convivir con nosotros (as) mismos (as) para encontrar en la soledad nuestra fortaleza o como un medio de conocimiento de uno mismo. Debemos aprender a convivir y trabajar con nuestros vacíos y soledad en silencio.

No se ha trabajado directamente el tema de la soledad, sino que en las mismas reflexiones que se han hecho sobre la dialéctica y la mayéutica, el de la comprensión del papel que tiene la Moira o el daimón, han permitido abordar y fomentar el aprender a

\footnotetext{
${ }^{8}$ PAZ, Octavio. El laberinto de la soledad. FCE, México, 2000, p. 22

${ }^{9}$ Ibid., p. 211
} 
encontrarse consigo mismas, buscar esos espacios y momentos en que puedan repetir algunas frases y que procuren encontrar una armonía en sí mismas, ante el conflicto de emociones y ante la situación de que no pueden hacer nada por los de afuera que son los suyos, salvo hablar con ellos si los visitan o aceptan una llamada. De esta forma, el hecho de apoyarlas a que escriban algo para sus seres queridos, que aprendan a escuchar al Otro y a procurar una reconciliación consigo mismas, ha ido generando ese espacio para aprender a sentirse y saberse solas, a manejar y canalizar su nostalgia hacia la actividad física, intelectual o artística, y, sobre todo, a aprender a estar en comunión consigo mismas.

En las sesiones se externan dudas y conflictos que las aquejan, pero el haber logrado que los Talleres exista la sororidad les permite encontrar un bálsamo y una piedra de toque para salir adelante. Dicha sororidad permite encontrar esa empatía, esa comunión y la solidaridad existente entre mujeres en el contexto en el que están inmersas: la reclusión en donde son revictimizadas y juzgadas de manera cruel por la sociedad machista en la que se encuentran.

La soledad, el sentirse y ser juzgadas como una "carga social" e inútil, así como el vacío interno que esto puede producir, se va agraviando y se potencializa en reclusión. En el interior del penal no existe amistad sino camaradería. Existe una constante prueba de resiliencia y de adversidades a enfrentar, de superar o vencer miedos y problemas que van desde bañarse a "jicarazos" (cubetadas) con agua fría; el no querer estar calladas y por eso prefieren gritar o cantar "a todo pulmón" porque aterran los momentos en silencio; el convivir en el interior de la estancia con tus compañeras en turno; asimilar la rutina de ser privada de su libertad; el soportar el lastre del desprecio social hacia quien está en reclusión; el estar a la defensiva y ver cómo otras personas si las visitan o si cuentan con dinero; lidiar con la idea del suicidio o de no perderse en el consumo de sustancias prohibidas; el desconfiar de los docentes, de las visitas de los grupos de Alcohólicos 
Anónimos (AA) o cristianos, entre otros, son situaciones que padecen en una amarga soledad.

En la mayoría de las ocasiones, no existe una comunión auténtica o una relación de amistad y apoyo duradera. Solo existe la nostalgia de todas aquellas cosas que disfrutaba antes de estar aquí. No en balde Paz considera que "la soledad es una pena, esto es, una condena y una expiación. Es un castigo, pero también una promesa del fin de nuestro exilio" ". Vemos cómo la gente está ensimismada escuchando su música, revisando cada minuto sus redes sociales, publicando lo fútil y efímero de su existencia en tiempo real, para ver los esfuerzos que la gente hace para escapar de su soledad y futilidad. A juicio de Paz, la soledad es "ruptura con un mundo caduco y preparación para el regreso y la lucha final" 11 . Uno no necesita estar privado de su libertad para reconocer que esto no es cierto. $\mathrm{Y}$ muchas veces al no existir un grupo, un apoyo real y sincero, una amistad que no surja de compartir la historia de sufrimiento y del vacío que implica estar encerrada en ese panóptico, es predecible que muchas mujeres terminen buscando un consuelo o apoyo en alguna actividad deportiva o académica, en la religión o en la farmacodependencia; que se "pague" por "sentir amor y compañía" o que crezca el resentimiento, hastío y absurdo de la sobrevivencia en el penal.

Pareciera que la misma reclusión, el diseño del penal y el sistema penitenciario tuvieran la finalidad de promover la soledad, el aislamiento y el vacío interno. No hay lugar en donde no sean observadas. Su reclusión no sólo es un castigo, sino que constituye en sí misma una ruptura radical y definitiva con el mundo de afuera. Ya sea que su salida se de a corto, mediano o largo plazo, el estigma de haber estado privadas de su libertad y que jamás puedan acceder a un trabajo al contar con una "carta de antecedentes

\footnotetext{
${ }^{10}$ Ibid., p. 212

${ }^{11}$ Ibid., p. 222
} 
penales" se convertirá en una herida expuesta y una marca indeleble y permanente. La mayoría de los asistentes y expositores de afuera les dicen que tienen tiempo para reorganizar su vida, para pensar y rediseñar su existencia, que procuren ser fuertes para encontrar esa expiación de la que habla Paz. Esto las lleva a dos opciones, por una parte, a ocupar este tiempo de reclusión para enfrentarse a sí mismas y así reinventarse, es algo que las puede llevar a su perdición al ver que no hay salida o que faltan muchos años para pensar en qué y cómo voy a salir, o por otra parte, en aprovechar esta oportunidad para lograr esa metamorfosis de su interior y convertirse en esa brújula que siga indicando el norte a la gente de afuera que las espera y que sufre por la injusticia, por no tener el dinero suficiente para la reparación del daño o que simplemente se quedo indefensa, sin esa mujer que era el sostén de su vida. Por estos y otros motivos, a lo largo de las sesiones se hacen ejercicios que no sólo producen catarsis, sino que les brindan los elementos para elaborar esa reinvención de su existencia en su exilio forzado en Santa Martha.

Volvamos a Elias, esa soledad, vacío o sentimiento que les ha hecho creer o sentirse un estorbo, así como creer que su existencia es inútil (la vida fútil y desechable que menciona Bauman), lleva a los accidentados, a las personas solitarias, a las personas privadas de su libertad y a los ancianos a esperar su muerte. La muerte siempre está presente en Santa Martha, desde la muerte de proyectos de vida, ilusiones, el ver crecer a sus hijos, el desarrollo profesional, el acompañar a los hijos en su graduación o en el nacimiento de sus hijos hasta la muerte real de amigos, familiares o compañeras de estancia. Se hace latente la muerte de las ilusiones como madre, mujer, amiga, hermana, vecina, etcétera. Se transpira la paulatina muerte de la fe y de las ilusiones. Muchas son acosadas por las muertes y fantasmas de personas que les hicieron daño pero que ya no estarán lastimado a otras personas... 
Aunado a este sentimiento de la muerte próxima o futura, metafórica o tangible, Elias afirma que esta soledad y sentimiento de "estar de sobra" es lo más cruel y ruin que ha hecho la sociedad moderna, pues difícilmente pueden encontrar un sentido al sinsentido que socialmente adquieren $y$ al que han sido etiquetados... Esto es lo que viven las personas privadas de su libertad. Ese eterno retorno de lo mismo, cada día, durante muchos años. La rutina mata. El panóptico, la estructura del mismo penal, con sus pasillos laberínticos, el recorrido cotidiano del "kilómetro" para pasar lista o ir a comer, hiere, ofende, humilla, exhibe y lacera, haciendo latente el sufrimiento.

Esa interiorización y normalidad del levantarse y ver qué ofrece el penal para hacer un día diferente: una función clown, asistir a la película que mensualmente trae alguna fundación donde ofrecen botanas y refrescos; acudir a algún festival de cualquier artista o fundación y, bailar en la explanada al ritmo de las canciones del sonidero; el inscribirse y asistir al taller de danza aérea, pintura, teatro, collage o box (que muchas de las internas son quienes imparten estas actividades); asistir a las clases que ofrecen las licenciaturas de la Universidad Autónoma de la Ciudad de México (UACM); ir al Taller de Filosofía o alguna actividad deportiva; ir con el grupo de cristianos que traen momentos de catarsis, paz interior y sanación momentánea; el pase de lista "al que no se puede ni debe faltar"; el escuchar gritos y diálogos de piso a piso; estar en plena clase y acostumbrarse a que buscan o vocean a alguien; esperar los alimentos o adquirir los insumos necesarios para preparar los alimentos del día; lavar y tender la ropa beige y azul marino; decidir si hoy me maquillo y arreglo para un día más o simplemente "me dejo ir"; confiar que cuando escuche mi nombre no sea el abogado que me pide más dinero sino tal vez, tal vez.. algún familiar que pasó todo ese protocolo para regalarnos unos minutos de su tiempo en "alguien como yo"... Son los susurros 
dolorosos, los lamentos, el "pan de cada día" que se transpira en Santa Martha...

Sobra decir que la desesperanza, apatía, frustración, enojo con la sociedad, Dios, algún conocido o el mundo son una constante. Se entiende el boom que tienen las prácticas religiosas, del cuarto y quinto paso de AA, de acudir a algún tipo de ritual y/o santería sacrificando alguna paloma; de inclinarse a las adicciones $o$ aferrarse a cualquier actividad que brinde "aire fresco", una esperanza, un medio de humanización y para recuperar el sentido al sinsentido en el que se encuentran estas mujeres. Esto es con lo que trabajamos en los Talleres de Filosofía: generar un espacio de reflexión y de apoyo desde las lecturas y contenidos filosóficos, buscando el otorgar un sentido al sinsentido de la vida en reclusión, un porqué y para qué seguir desde la historia de cada una de las vidas que ellas mismas deben tejer, y aunque el número de asistentes es mínimo (cada cuatrimestre tenemos hasta 30 inscritas de las cuales 15 son constantes de una población en el penal de más de 1300 mujeres), se ha avanzado de manera significativa y con resultados insospechados.

Muchas de ellas han encontrado en la literatura y la poesía su refugio y piedra de toque y ahora escriben sus propios cuentos y poemas; otras con el planteamiento del existencialismo o vitalismo han ido resignificando su estancia o existencia en Santa Martha; otras llevan a cabo los ejercicios de ataraxia y ascesis planteadas en las escuelas helénicas del cinismo, epicureísmo o estoicismo; algunas se han convertido en replicadoras de lo visto en los talleres con sus familiares y sus compañeras de la estancia, y, la gran mayoría sostiene que estas clases han hecho soportable su estadía en el penal, que han recuperado los motivos para salir adelante por lo que vuelven a preocuparse y ocuparse de sí mismas, o que les hubiera gustado saber de esto y tal vez no hubieran pisado este centro penitenciario. Clase tras clase nos hacen saber del agradecimiento, ese llanto y abrazo compartido que ha generado 
una catarsis y sororidad en el interior del Taller, al grado que comparten con uno hasta sus alimentos. Estas acciones, actitudes y detalles muy significativos. Ahora ellas escriben sus impresiones de cada clase, investigan y leen en la biblioteca, participan y tratan de aplicar en la medida de lo posible los contenidos de las sesiones. De esta forma, la soledad, culpa, el proceso de su estancia en el penal, el duelo y abandono que carcomen y merman las ganas y motivos por el que uno debe salir adelante, se han ido aligerando con las sesiones del taller de Filosofía. Paulatinamente han aprendido a convivir con su soledad, a hacer de ella una fortaleza y a procurar salir adelante, independientemente de que vayan a visitarlas o no, o de que algunas les falten unos meses o muchos años para salir en libertad. Ciertamente no es fácil y cada día se convierte en una prueba a su resistencia física, emocional y a su voluntad. ¿De dónde obtienen esa fuerza? Algunas lo encuentran en los suyos (que casi no ven); en los hijos que confían volver a ver; en Dios, en alguna otra situación o factor. Algunas lo logran, otras no. La reclusión es una prueba que forja el carácter, que te reivindica como humano o te hunde, $\mathrm{y}$, hace creer que perdiste la dignidad y calidad humana... Veamos un escrito que me proporcionó D’Kiim Hdez que es una de las integrantes de este Taller y que fue fruto de las reflexiones de lo que le han dejado las sesiones previas a este escrito y que considero resumen lo descrito con antelación:

\section{Lo insospechado}

Me muevo como un remolino inesperado, que decrece escucho el eco de las voces que se abren paso entre lúgubres pasillos,

entre los escondrijos por los cuales se asoman los ojos temerosos, de los entes que enloquecen ante el fulgor de la luz, los eslabones que presionan laceran la piel dejando pulular insectos tan pestilentes y repulsivos que presurosos comienzan a devorar. Tanto que decir y nada a la vez, faltan las palabras, la mente, se niega la vida, es incierta, hace claudicar, muchos se suicidan 
otros a tantos matarán; veo la furia de los impulsos maquiavélicos, fantasmas turbadores que salen de todos lados; la voz, los ojos, las manos

luego se esfuman, no me gusta lo que hay, no me satisface lo que escribo,

no me agrada ver sufrimiento, estoy obligada a aceptar vivencias... ¡así nada más!

Sufrir metamorfosis no sería nada fatal, necesario sería mutar, conocer un aspecto de lo desconocido, en absoluto temer a la oscuridad, poder domesticar a la fiera embravecida, que lo incierto deje de atormentar

que los monstruos horrorosos no quiten el sueño nunca más, que las medusas

y los tritones sean mitología histórica, que los adultos no distorsionen jamás.

La reina roja habría triunfado con solo gritar.

Si la magia ilusión no fuera ¿cuál sería la realidad?

lo indescriptible aún no s puede dibujar, lo posible se puede hablar. en este laberinto he hablado con demonios queriéndose exorcizar, con duendes avariciosos que de repente osan robar, con fieras enceguecidas

que a cualquier hora pretenden cazar, con brujas disfrazadas participando

en orgías, realizando rituales que tú no lo creerás.

Caminar en el fango temiendo no salir, estar cerca del fuego

casi me logran quemar $\mathrm{y}$ ¡he bebido veneno! Sintiendo de a poco morir

lo oscuro, lo extraño, lo cruel está siempre detrás, no todo lo que ves

es lo real, observa con denuedo, observa nada más, un solo instante magia parecerá; lo inaudito, lo extraordinário es quizá solo parte de lo que no conocerás. ${ }^{12}$

$* * * *$

${ }^{12}$ HDEZ, D’Kiim. Lo insospechado. Texto inédito, 2018 
¿Qué se puede concluir de esta experiencia de la impartición de los Talleres de Filosofía en Santa Martha? A nivel personal, la impartición de estas sesiones que tienen como objetivo proporcionar elementos, nociones y aprendizajes que sean significativos para personas privadas de su libertad ha sido uno de los mayores retos a los que me he enfrentado. Hablar de contenidos filosóficos que sean relevantes y útiles ante el escenario en que se encuentran ha sido gratificante, ya que me he percatado del poder e impronta que tienen muchos discursos filosóficos en situaciones limítrofes, que pueden hacer que la vida de una persona sea resignificada y que la clase les "haga el día" o que muchas de las palabras, gestos, ejemplo y actitudes que ellas ven en las sesiones tienen una resonancia más allá de las paredes del panóptico de Santa Martha.

A las chicas que han obtenido su libertad, recuperar la vida que tenían antes después del tránsito de reclusión no ha sido sencillo ni fácil, pero la gran mayoría coincide en que muchos de los contenidos no sólo le permitieron sobrevivir en Santa Martha, sino que constituyen parte de las bases para su reinserción social, familiar y personal. Muchas de ellas han pensado en estudiar la carrera de filosofía, buscan continuar con su Taller de Filosofía y nos comparten mensajes de agradecimiento por lo hecho en clases y porque los frutos se están dando en su reinvención y adaptación a continuar fuera del penal.

Recibir un aplauso, una lágrima o llanto compartido, un agradecimiento, un abrazo o percibir el respeto hacia la filosofía y mi persona son cosas sumamente conmovedoras e indescriptibles, que me obligan a seguir haciendo algo más por ellas y por tantos otros sectores excluidos y marginados de la sociedad. Sacar a la filosofía de los ámbitos académicos y llevarlos a la periferia o a lugares olvidados y marginados me hace repensar lo que aprendí en mi formación universitaria, es un conocimiento vivo y tan impactante que uno llega a comprender que es posible hacer de la 
filosofía una forma de vida. Ciertamente muchas sesiones son agotadoras pues se han convertido en un público exigente y que son privilegiadas por las personas que han sumado sus voces a los Talleres y que siempre tienen una sinergia semejante a la de los "besos de los dementores" de Harry Potter (si se me permite esa analogía no académica) que terminan agotando al ponente, pero con la satisfacción o con la herida de que hay tanto por hacer y que se carecen de manos y de voluntad para trabajar con ellas y tantos otros sectores vulnerables de la sociedad.

En lo que se refiere al Taller, estas sesiones han servido de paliativo para personas que se encuentran en ciertos momentos críticos de sus vidas; al hecho de cada tema se ha convertido en un aliciente para que decidan concluir sus estudios de bachillerato e iniciar los cursos universitarios (siempre y cuando puedan pagar los costos que tienen los exámenes y certificaciones); que se ha convertido en el espacio por excelencia en el que se han apropiado y empoderado de su palabra, voz y pensamiento; que fue el espacio en donde Lulú nos compartió una pieza de baile de ballet, en donde Selene canto "Yo te nombro libertad", en donde escuchamos los testimonios de Irma ante los problemas y fantasmas con los que está trabajando y hoy es el sostén de muchas de sus compañeras, en donde Mercedes nos dijo que está aprendiendo a convivir con su lupus, o que las "guerreras" fueron campeonas en la primer temporada que dirigió el también coach Marco Antonio López Cortés; así como también que estas sesiones les ha brindado elementos y nociones para reflexionar sobre sí mismas y para tener un tema del qué hablar y que sea propositivo para los suyos; al hecho de que en ciertas sesiones han tenido la apertura para mostrarse como son y recibir los abrazos, la sororidad y empatía que les hacía falta, o que simplemente, es un oasis de libertad en la rutina e inercia del penal.

Desgraciadamente no todo "es miel sobre hojuelas", ya que se ha tenido que enfrentar la muerte o el "suicidio" de familiares, 
compañeras de la estancia o integrantes del Taller; a escuchar la preocupación porque alguno de sus hijos fue atropellado, perdió el trabajo, va a ser padre o está hospitalizado y no están a su lado para compartir estos momentos tan importantes; que posiblemente muchas de ellas no salgan a estudiar una carrera de filosofía pero que se pudo vivenciar y aplicar la filosofía como una forma de vida y un arte de redefinir su existencia. No se han producido los grandes ensayos o disertaciones más profundas y elevadas, pero el cambio actitudinal y el poder encontrar una dirección y sentido en el calvario en el que se encuentran son de las cosas más gratificantes e intangibles que se han dado en la enseñanza y difusión de la filosofía con las personas privadas de su libertad. Confío en que este Taller siga siendo esa luz que permita redireccionar, reinventar y resignificar la vida y proyecto de estas mujeres.

\section{Referencias}

BAUMAN, Zygmunt. Vidas desperdiciadas. La modernidad y sus parias, Paidós, Buenos Aires, 2005, p. 32

GUERRA GARCÍA, Selene Patricia: "Mi experiencia en el taller de filosofía de Santa Martha Acatitla", disponible on-line en https://cefilibe.wordpress.com/page/1/ (último acceso 19 de octubre de 2018).

HDEZ, D’ Kiim. Lo insospechado. Texto inédito, 2018.

ELIAS, Norbert. La soledad de los moribundos. FCE, México, 1987.

PAZ, Octavio. El laberinto de la soledad. FCE, México, 2000. 